\title{
PENATALAKSANAAN PASIEN DENGAN KONTUSIO PARU
}

\author{
Randolph Siahaan ${ }^{1,2}$, Maharani ${ }^{3}$ \\ ${ }^{1}$ Departemen Anestesiologi Fakultas Kedokteran Universitas Kristen Indonesia Jakarta \\ ${ }^{2}$ RSUD dr. Chasbullah Abdulmajid KOTA BEKASI \\ ${ }^{3}$ Program Studi Profesi Dokter Fakultas Kedokteran Universitas Kristen Indonesia, Jakarta \\ email : randolph_siahaan@yahoo.com
}

\begin{abstract}
ABSTRAK
Pendahuluan : Kontusio paru adalah manifestasi trauma tumpul toraks yang paling umum terjadi. Kontusio paru paling sering disebabkan trauma tumpul pada dinding dada secara langsung yang dapat menyebabkan kerusakan parenkim, edema interstitial dan perdarahan yang mengarah ke hipoventilasi pada sebagian paru. Kontusio paru juga dapat menyebabkan hematoma intrapulmoner apabila pembuluh darah besar didalam paru terluka dan memiliki potensial menyebabkan kematian. Proses, tanda dan gejala mungkin berjalan pelan dan makin memburuk dalam 24 jam pasca trauma. Penatalaksanaan pada pasien perlu dilakukan segera dengan memastikan patensi jalan napas, pemberian analgetik, ventilasi mekanik dan terapi pendukung lainnya seperti pemberian antibiotik dan terapi cairan untuk mencegah terjadinya komplikasi yang terjadi.
\end{abstract}

Tujuan : Melaporkan penatalaksanaan kasus kontusio paru di ICU.

Laporan Kasus : Seorang pasien laki-laki 56 tahun datang ke IGD RSCAM Bekasi dengan keluhan utama nyeri pada dada kanan dan sesak. 2 hari sebelum masuk RS, pasien terjatuh dari pohon dengan ketinggian \pm 5 meter. Pasien terjatuh dengan posisi bagian depan tubuh terlebih dahulu. Sesak (+), pingsan, muntah (-), nyeri dada (+). Pasien lalu dibawa ke RS GJ, dilakukan foto toraks dan pemasangan chest tube. Setelah dirawat 2 hari, pasien dirujuk ke IGD RSCAM BEKASI, foto toraks di RS GJ menunjukkan adanya Hematopneumotoraks kanan dan terlihat chest tube pada posisinya. Pasien tiba \pm pukul 13.42, setelah diobservasi \pm 6 jam, pasien dikonsulkan ke bagian Anestesi pada pukul 20.00, dan ditemukan kesadaran pasien komposmentis, dengan Tekanan darah 130/90, laju nadi 120x/menit dan frekwensi napas pasien 34-38x/menit (O2 101/menit dengan NRM), SpO2 88\%, VAS (Visual Analog Score) 6-8/10. Pasien kemudian diintubasi atas indikasi Hematopneumotoraks kanan + kontusio paru bilateral + impending gagal napas post CTT + fraktur costae 7-8 aspek posterior kanan, 6 aspek lateral kanan + flail chest. Pasien kemudian dirawat ke ICU.

Kesimpulan : Penatalaksanaan pada pasien perlu dilakukan segera untuk mencegah terjadinya komplikasi yang terjadi, yaitu dengan memastikan patensi jalan napas, pemberian analgetik, ventilasi mekanik dan terapi pendukung lainnya seperti pemberian antibiotik dan terapi cairan untuk mencegah terjadinya komplikasi yang terjadi.

Kata Kunci : kontusio paru, trauma toraks. 


\begin{abstract}
Introduction : Lung Contusion is the most common manifestation from chest trauma. The most common cause of lung contusion is blunt trauma to the chest wall directly which can do damage to the parenchim, interstitial edema and haemorrhage that can lead to hypoventilation of the lung. Lung contusion can also lead to intra pulmonary haematoma if it involved the great vessel of the lung and potentially can lead to death. The process, signs and symptoms might be delayed and can be worsening 24 hours post trauma. Management for the patient must be done as soon as possible with securing airway patency, analgetics, mechanical ventilation and other supportive therapy for example iv antibiotics and fluid therapy to prevent further compications.
\end{abstract}

Objective : To report a case of lung contusion in ICU

Case Report : A fifty six year old man presented at ER with chest pain and dyspnoe. Patient had a history falling from 5 metres trees 2 days before. He fell with his front body landed first. Dyspnoe (+), fainted (-), chest pain (+). Patient then taken to the GJ Hospital, he had chest $\mathrm{x}$ ray examination and chest tube placing done. After hospitalized for 2 days, then he had been taken to the RSCAM Bekasi Emergency Room, the chest $\mathrm{x}$ ray from GJ Hospital shows right hematopneumothorax and chest tube in the right position. Suddenly at 13.42 PM, after being observed for about 6 hours, he then had been consulted to the anesthesia department at $8 \mathrm{PM}$, from examination he looks fully concious, with BP 130/90, HR 120x/min and RR 34-38x/min (with O2 10L/min NRM), SpO2 88\%, VAS 6-8/10. Patient then intubated for indication of right Hematopneumothorax + bilateral lung contusion + impending respiratory failure post chest tube placement + fracture $7-8^{\text {th }}$ right posterior costae/ rib, $6^{\text {th }}$ right lateral costae/rib + flail chest. Patient then hospitalized in ICU.

Conclusion : Patient Management needs to be done as soon as possible to prevent further complications, that consist securing airway patency, analgetics, mechanical ventilation and other supportive therapy for example iv antibiotics and fluid therapy to prevent further compications.

Keyword : lung contusion, chest trauma. 


\section{Pendahuluan}

Trauma toraks tumpul dapat menyebabkan banyak penyakit serius. Dari jumlah tersebut, kontusi paru dapat menyebabkan morbiditas dan mortalitas yang signifikan jika tidak dikenali secara dini dan ditangani dengan tepat. ${ }^{1}$ Sementara kasus lain yang segera mengancam jiwa mungkin pada awalnya terlihat kelainan klinis dan kelainan radiografi, dari kontusio paru dapat terjadi secara tertunda. Meskipun tingkat kesakitan dan mortalitas untuk kontusio paru tidak banyak berubah dalam beberapa dekade terakhir, pengenalan awal terhadap faktor risiko, gejala, dan tanda, juga sebagai pengobatan agresif dapat mengurangi kerugian bagi pasien. Baru-baru ini, telah ada beberapa perdebatan mengenai cara terbaik untuk mengelola paru-paru yang bergantung pada ventilator, dan pilihan disposisi untuk pasien yang kontusiasinya hanya dapat dilihat pada tomografi computer. $^{2}$

Kontusio paru adalah manifestasi trauma tumpul toraks yang paling umum terjadi. Kontusio paru paling sering disebabkan trauma tumpul pada dinding dada secara langsung yang dapat menyebabkan kerusakan parenkim, edema interstitial dan perdarahan yang mengarah ke hipoventilasi pada sebagian paru. Kontusio juga dapat menyebabkan hematoma intrapulmoner apabila pembuluh darah besar didalam paru terluka. Kontusio paru memiliki potensial menyebabkan kematian. Kontusio paru biasanya disebabkan oleh trauma tumpul tetapi juga bisa diakibatkan oleh ledakan atau gelombang kejut yang berhubungan dengan trauma tembus. Kekuatan yang terkait dengan trauma toraks tumpul dapat mengenai ke parenkim paru. Hal ini menyebabkan kontusio paru, ditandai dengan perkembangan infiltrat paru dengan perdarahan ke dalam jaringan paru-paru. ${ }^{3}$

Kontusio paru terjadi pada sekitar 20\% dari pasien trauma tumpul dengan Skor Keparahan Cedera lebih dari 15 dan itu adalah cedera dada yang paling umum pada anak-anak. Angka mortalitas dilaporkan 10 sampai $25 \%$, dan $40-60 \%$ dari pasien akan memerlukan ventilasi mekanis. Komplikasi luka memar paru ARDS, seperti yang disebutkan, dan kegagalan pernafasan, atelektasis serta pneumonia. ${ }^{4}$

\section{Laporan Kasus}

Seorang pasien laki-laki 56 tahun datang dengan keluhan utama nyeri pada dada kanan dan sesak. 2 hari sebelum masuk RS, pasien terjatuh dari pohon dengan ketinggian \pm 5 meter. Pasien terjatuh dengan posisi bagian depan tubuh terlebih dahulu. Sesak $(+)$, pingsan, muntah (-), nyeri dada (+). Pasien lalu dibawa ke RS GJ, dilakukan foto toraks dan pemasangan chest tube. Setelah dirawat 2 hari, pasien dirujuk ke IGD RSCAM BEKASI, foto toraks di RS GJ menunjukkan adanya Hematopneumotoraks kanan dan terlihat chest tube pada posisinya. Pasien tiba \pm pukul 13.42, setelah diobservasi \pm 6 jam, pasien dikonsulkan ke bagian Anestesi pada pukul 20.00, dan ditemukan kesadaran pasien komposmentis, dengan TD 130/90, HR 120x/menit dan RR pasien 34-38x/menit (O2 101/menit dengan NRM), SpO2 $88 \%$, VAS skor 6-8/10. Pasien kemudian diintubasi ai Hematopneumotoraks kanan + kontusio paru bilateral + impending gagal napas post CTT + fraktur costae 7-8 aspek posterior kanan, 6 aspek lateral kanan + flail chest. Setelah intubasi dan dihubungkan dengan sirkuit Jackson Reess (assist), hemodinamik stabil dengan TD 134/72, HR 105x/menit dengan RR 3438x/menit dan $\mathrm{SpO} 2$ 95-96\%. Namun pasien masih gelisah dikarenakan nyeri, pasien diberikan analgetik morfin $5 \mathrm{mg} / \mathrm{jam}$ dan sedasi dengan midazolam 2mg/jam. Cairan maintenance dengan RL $110 \mathrm{ml} / \mathrm{jam}$. Pasien naik ke ICU 3 jam kemudian (pukul 23.00).

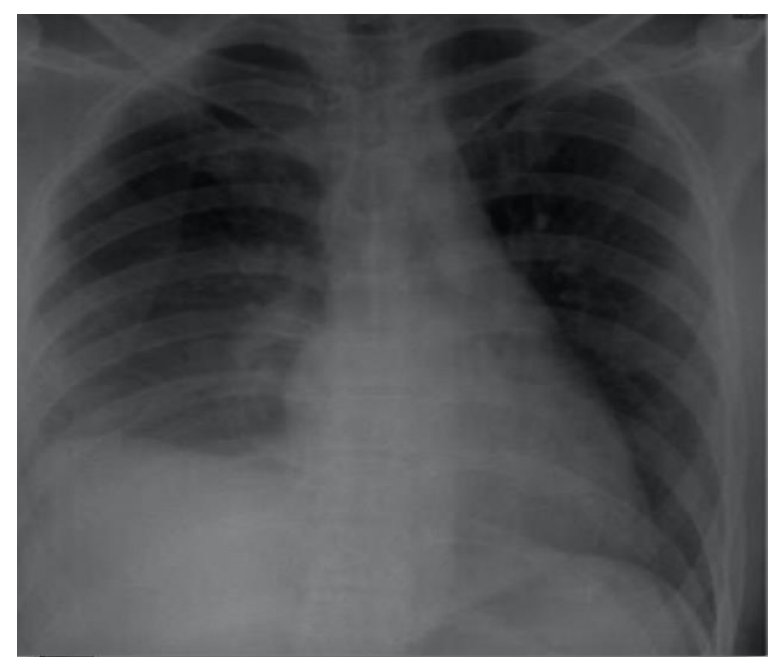

Gambar 1. Foto toraks 11/7/2020 di IGD

Saat tiba di ICU keadaan umum pasien relatif stabil, kesadaran $R A S S+1$, namun terjadi peningkatan tekanan darah dengan TD (invasif dipasang di ICU) 
160-175/80, HR 80-120x/menit, RR 20-24x/menit, SpO2 94-96\% dengan CPAP PEEP 6 FiO2 55\%. Namun dengan penambahan pemberian analgetik Dexdeketomidin, tekanan darah berkisar antara 100120/60-65 mmHg. Pasien mendapat terapi Feeding 8 x 20ml D10\%. Dilanjutkan dengan 400ml D10\%, dengan antibiotik Ceftriaxon 2 × 2 gr, serta diberikan sedasi dan analgetik Dexdeketomidin 0.2 $\mathrm{mcg} / \mathrm{kg} / \mathrm{jam}$, Morfin $20 \mathrm{mcg} / \mathrm{kg} / \mathrm{jam}$. Posisi kepala Head Up 30 derajat dan diberikan terapi ulseratif Omeprazole 40mg/12 jam. Terapi lain diberikan Nebulizer Combivent + Flixotide/ 6 jam serta N Acetylcystein 200mg tab/ 8 jam. Dari hasil Rontgen didapatkan pasien mengalami kontusio paru bilateral dengan hematotoraks kanan. fraktur iga 8-9 aspek posterior, 6-9 aspek lateral kanan dan emfisema subkutis di hemitoraks bawah kanan serta CTT setinggi ICS 6 aspek posterior.

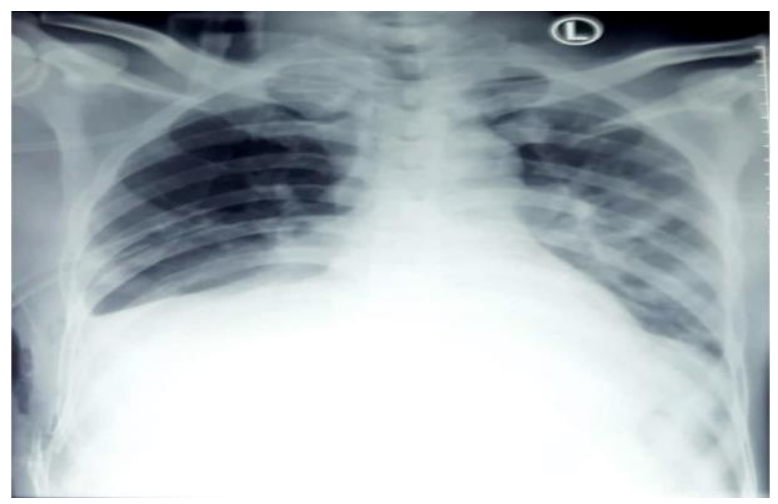

Gambar 2. Foto toraks 11/7/20 HP 1, 12 jam setelah foto 1

Pada hari perawatan kedua, keadaan umum pasien relatif stabil namun terjadi peningkatan suhu sampai dengan 39 derajat. Kesadaran RASS -1, TD 110120/70-80, HR 80-110x/menit, RR 20-24x/menit, SpO2 94-96\% dengan CPAP PEEP 6 FiO2 55\%. Diberikan ekstra Paracetamol 1 gram. Pasien sudah mendapat terapi feeding via NGT 1250 kkal. Terapi lain relatif sama kecuali dosis analgetik Dexdeketomidin dinaikkan menjadi $0,3 \mathrm{mcg} / \mathrm{kg} / \mathrm{jam}$, dengan target CPOT 1 serta penambahan asam tranexamat $3 \times 500 \mathrm{mg}$ dan vit $\mathrm{K}$. Dari pemeriksaan radiologi juga belum ada perbedaan berarti, yaitu Kontusio paru bilateral dengan hematotoraks kanan. DD/ efusi pleura kanan, belum tampak perbaikan dengan fraktur iga 8-9 aspek posterior, 6-9 aspek lateral kanan dan emfisema subkutis di hemitoraks bawah kanan serta CTT setinggi ICS 6 aspek posterior.

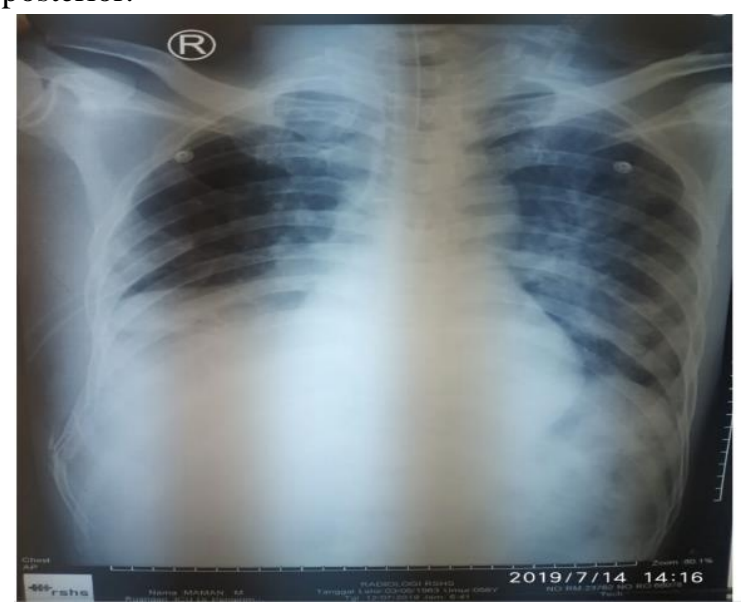

Gambar 3. Foto toraks 12/7/20 HP 2

Pada hari perawatan ke 3 dan 4 , keadaan umum pasien relatif stabil, RASS -1,TD 115-1120/70-80, HR 80-100x/menit, RR 20-24x/menit , SpO2 94-96\%, dengan CPAP PEEP 6 FiO2 55\%. Pada hari ke 4 dilakukan ekstubasi dan pencabutan CTT setelah diklem terlebih dahulu dan untuk oksigenisasi dipasang sungkup 12L/menit. Suhu masih naik turun dengan suhu tertinggi 38,5 derajat. Pemberian obat ditambah dengan antipiretik Paracetamol 1 gram/ 6 jam. Pasien mendapat terapi yang sama namun jumlah kalori ditambah menjadi $1500 \mathrm{kkal} / 24$ jam masih dengan NGT. Dari pemeriksaan rontgen dapat disimpulkan sudah terdapat perbaikan. Yaitu kontusio paru bilateral perbaikan, hematotoraks kanan perbaikan, fraktur iga 8-9 kanan, aspek posterior, fraktur iga 6-9 kanan, aspek lateral, emfisema subkutis di daerah hemitoraks bawah kanan perbaikan.

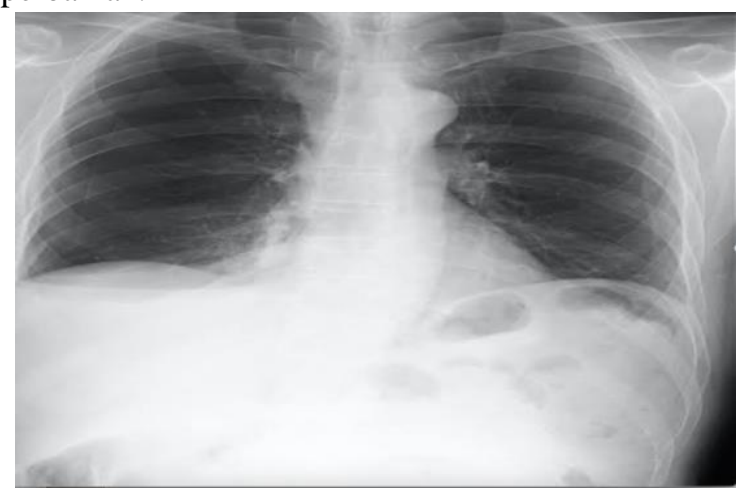

Gambar 4. Foto toraks 14/7/2020 HP 4

Pada hari perawatan ke 5, keadaan umum pasien semakin baik, kesadaran CM, dengan tekanan darah TD 110-125/70-80, HR 75-100x/menit, RR 20- 
24x/menit, SpO2 95-97\%, masih dengan sungkup, namun sudah bisa diturunkan sampai $81 /$ menit. Pemberian analgetik dexdeketomidin diganti dengan ketorolac 3x30mg dengan terapi lain tetap dilanjutkan.

Sampai kemudian pada hari perawatan ke 6, keadaan umum pasien menjadi semakin baik lagi, kesadaran CM, dengan tekanan darah TD 110-125/70-80, HR 75-100x/menit, RR 20-24x/menit, SpO2 95-97\%, oksigenisasi sudah nyaman dengan nasal kanul 31/menit dan nebulizer diganti dengan Nacl 0,9\%. Pada hari ke 6 ini pasien mulai makan makanan padat. Selanjutnya pada hari ke 7 analgetik morfin dihentikan dan pasien siap untuk dipindahkan ke ruangan biasa dengan terapi yang tersisa hanya antibiotik ceftriaxon $2 \times 2$ gr dan pemberian nebulizer Nacl 0,9\%.

\section{PEMBAHASAN}

Paru-paru adalah salah satu organ sistem pernapasan yang berada di dalam kantong yang di bentuk oleh pleura parietalis dan viseralis. Kedua paru sangat lunak, elastik dan berada dalam rongga torak. Masing-masing paru memiliki apeks yang tumpul yang menjorok ke atas mencapai bagian atas iga pertama. ${ }^{5}$

Kontusio paru adalah kerusakan langsung atau tidak langsung dari parenkim paru-paru yang menyebabkan edema atau alveolar hematoma dan hilangnya struktur fisiologis dan fungsi paru-paru sehingga menyebabkan pertukaran gas berkurang, resisten pembuluh darah paru meningkat, penurunan pemenuhan kebutuhan paru selama 24 jam. 3,6

\section{Penyebab Kontusio Paru}

Kontusio paru terjadi pada sekitar 20\% dari pasien trauma tumpul dan itu adalah cedera dada yang paling umum pada anak-anak. Angka mortalitas berkisar 10 sampai $25 \%$, dan $40-60 \%$ dari pasien akan memerlukan ventilasi mekanis. Komplikasi luka memar paru ARDS, seperti yang disebutkan, dan kegagalan pernafasan, atelektasis dan pneumonia. Penting untuk dicatat bahwa temuan ini awalnya mungkin tidak ada segera setelah cedera primer. Mereka mungkin berkembang dengan cepat pada beberapa, tetapi pada yang lain mungkin membutuhkan waktu hingga 48 jam untuk terwujud. Gejala yang memburuk selama 24 jam setelah cedera menandakan prognosis jangka pendek dan jangka panjang yang lebih buruk.

Biasanya, bila terjadi kematian, disebabkan dari cedera lainnya, seperti cedera otak traumatis umum. ${ }^{4,7}$

Penyebab utama terjadinya kontusio paru adalah trauma tumpul pada dada. Penyebab lain: ${ }^{8}$

1. Kecelakaan lalu lintas

2. Cedera ledakan atau gelombang kejut yang terkait dengan trauma penetrasi.

3. Flail chest

4. Dapat pula terjadi pada trauma tajam dengan mekanisme perdarahan dan edema parenkim.

Kontusio paru menghasilkan perdarahan dan kebocoran cairan ke dalam jaringan paru-paru, yang dapat menyebabkan paru menjadi kaku dan kehilangan elastisitas normal. Kandungan air dari paru-paru meningkat selama 72 jam pertama setelah cedera, berpotensi menyebabkan edema paru pada kasus yang lebih serius. Sebagai hasil dari ini dan proses patologis lainnya, memar paru berkembang dari waktu ke waktu dan dapat menyebabkan hipoksia. $^{9}$

Kontusio paru dapat menyerupai ARDS, dimana keduanya berespon buruk terhadap fraksi oksigen inspirasi yang tinggi (FiO2). ${ }^{10}$ Yaitu takikardi, dispnoe, bronchoorhea/ sekresi bercampur darah, takipnea, hipoksia, perubahan kesadaran. Namun sebanyak setengah dari kasus tidak menunjukkan gejala pada presentasi awal. Pada kasus berat, gejala dapat terjadi secepat tiga atau empat jam setelah trauma yaitu hipoksemia dan sianosis. ${ }^{10,16}$

\section{Pemeriksaan untuk menegakkan diagnosis}

Pada kasus kontusio paru pemeriksaan yang perlu dilakukan adalah :

\section{Rontgen Toraks}

Menunjukkan memar paru yang berhubungan dengan patah tulang rusuk dan emfisema subkutan. Ro thoraks menunjukkan gambaran Infiltrat, tanda infiltrat kadang tidak muncul dalam 12-24 jam. ${ }^{11}$

Sinar $\mathrm{x}$ dada adalah tes lini pertama yang didapat pada trauma thoraks tumpul untuk menilai cedera paru atau toraks. Perlu dilakukan pemeriksaan berulang dan pencitraan lebih lanjut jika gejala terus berlanjut. Tinjauan bagan prospektif oleh Tyburski dkk menunjukkan bahwa sampai $25 \%$ pasien yang awalnya didiagnosis dengan kontusi paru di 
departemen emergensi mengalami perburukan klinis dan radiografi selama 24 jam.

2. Computed tomography (CT-Scan)

Akan menunjukkkan gambaran kontusio lebih awal. Computed tomography dapat menggambarkan cedera paru-paru dan kontusio yang tidak terlihat pada rontgen dada awal. Karena CT mudah didapat, sangat akurat, dan mudah didapat di fasilitas gawat darurat, hal ini dianggap sebagai gold standar untuk diagnosis kontusio paru. Namun, pada pasien dengan kontusio paru ringan yang didiagnosis dengan sinar $\mathrm{X}$ dada dan sedikit gejala klinis, CT mungkin tidak diperlukan.

\section{USG}

Karena ultrasound telah menjadi modalitas pencitraan yang lebih umum, ultrasound paru telah bermanfaat di tempat tidur imaging dari berbagai cedera paruparu seperti pneumotoraks, edema paru, dan pneumonia.

Pemeriksaan ini adalah tambahan yang berguna untuk membantu diagnosis saat sinar $\mathrm{X}$ dada dihentikan, CT scan tidak tersedia, atau pasien terlalu tidak stabil untuk dibawa ke ruang radiologi. ${ }^{12}$

\section{Penatalaksanaan Kontusio Paru}

Penatalaksanaan utama dari kasus kontusio paru adalah mempertahankan patensi jalan napas, intubasi ET jika diperlukan untuk dapat melakukan penyedotan dan memasang ventilasi mekanik dengan continuous positive end-expiratory pressure. ${ }^{13}$

Penatalaksanaan pada kontusio paru yang utama selain mempertahankan patensi jalan napas adalah pemberian analgetik.

Kontrol nyeri yang optimal merupakan pertimbangan manajemen yang penting pada pasien dengan cedera toraks yang signifikan dan kontusi paru. Pasien harus bisa melakukan nafas dalam-dalam yang efektif . Menggabungkan cara analgesia yang berbeda, seperti epidural, $P C A$ opioid, obat antiinflamasi nonsteroid (NSAID), dan asetaminofen, meningkatkan ventiasi dan fisioterapi. Anestesi epidural dan bahkan blok saraf interkostal juga berguna pada pasien dengan persisten pernapasan paradoksal.

Ventilasi mekanis mungkin diperlukan jika memar paru menyebabkan oksigenasi yang tidak memadai. Ventilasi tekanan positif, di mana udara dipaksa masuk ke dalam paru-paru, diperlukan bila oksigenasi secara signifikan terganggu. Noninvasif ventilasi(NIV), continuous positive airway pressure
(CPAP) dan (BiPAP), dapat digunakan untuk meningkatkan oksigenasi dan mengobati atelektasis. 14,15

Selain mempertahankan patensi jalan napas dan anlgetik, pemberian antibiotik dengan kebutuhan yang jelas biasanya dianjurkan. Untuk orang-orang yang berisiko sangat tinggi infeksi berkembang, dahak dapat dikultur untuk menguji keberadaan infeksi-bakteri penyebab.

Mengontrol rasa sakit adalah cara lain untuk memfasilitasi pengurangan sekresi. Sebuah cedera dinding dada bisa membuat batuk menyakitkan, meningkatkan kemungkinan bahwa sekresi akan menumpuk di saluran udara . Luka dada juga berkontribusi terhadap hipoventilasi (pernapasan tidak memadai) karena gerakan dinding dada yang terlibat dalam pernapasan memadai menyakitkan. Keterbatasan ekspansi dada dapat menyebabkan atelektasis, lebih lanjut mengurangi oksigenasi dari darah Analgesik (obat nyeri) dapat diberikan untuk mengurangi rasa sakit. Injeksi anestesi ke saraf di dinding dada, yang disebut blokade saraf, pendekatan lain untuk manajemen nyeri ini tidak menekan pusat respirasi. Terapi cairan pada individu dengan kontusio paru masih menjadi kontroversi. Cairan yang berlebihan dalam sistem peredaran darah (hipervolemia) dapat memperburuk hipoksia karena dapat menyebabkan kebocoran cairan dari kapiler sehingga dapat menyebabkan edema paru. Namun, pada volume darah yang rendah (hipovolemia) yang dihasilkan dari cairan yang tidak mencukupi memiliki dampak yang lebih buruk, berpotensi menyebabkan syok hipovolemik, karena orang-orang yang telah kehilangan sejumlah besar darah, cairan resusitasi sangat diperlukan.

Pada pasien ini, terjadi hematopneumotoraks dengan kontusio paru + fraktur iga multipel + flail chest Pasien baru dibawa ke RS pada hari ketiga. Hal ini hampir sesuai dengan teori yaitu proses, tanda dan gejala mungkin berjalan pelan dan makin memburuk dalam 24 jam paska trauma ${ }^{10,16}$, bahkan kandungan air masih bisa meningkat sampai dengan 72 jam paska trauma ${ }^{9}$ Penatalaksanaan terhadap pasien dengan hematopneumotoraks dengan kontusio paru + fraktur iga multipel + flail chest, baik dari IGD sampai dengan perawatan pasien di ICU dengan menonjolkan 3 terapi utama yaitu patensi jalan napas, analgetik dan pemberian bantuan ventilasi mekanik selama beberapa hari, juga sudah tepat, ditambah 
juga dengan beberapa terapi suportif lainnya seperti pemberian cairan dan pemeriksaan lab dan radiologi berkala. Sehingga pasien cepat diekstubasi dan pindah dari ICU.

\section{Kesimpulan}

Kontusio paru adalah kerusakan pada parenkim paru yang menyebabkan edema dan akumulasi darah di ruang alveolar dan hilangnya struktur dan fungsi paru normal. Kontusio paru biasanya disebabkan oleh trauma tumpul tetapi juga bisa diakibatkan oleh ledakan atau gelombang kejut yang berhubungan dengan trauma tembus. Kekuatan yang terkait dengan trauma toraks tumpul dapat mengenai ke parenkim paru. Hal ini menyebabkan kontusio paru, ditandai dengan perkembangan infiltrat paru dengan perdarahan ke dalam jaringan paru-paru. Diagnosis dapat ditegakkan dengan pemeriksaan penunjang seperti rontgen toraks, CT scan, USG. Penatalaksanaan pada pasien perlu dilakukan segera untuk mencegah terjadinya komplikasi yang terjadi, yaitu dengan memastikan patensi jalan napas, pemberian analgetik, ventilasi mekanik dan terapi pendukung lainnya seperti pemberian antibiotik, terapi cairan dan terapi fisik dada untuk mencegah terjadinya komplikasi yang terjadi.

\section{DAFTAR PUSTAKA}

1. Reade MC. Trauma Toraks dan Manajemen Ventilasi pada Pasien Cedera Kritis. Perawatan Kritis Trauma dan Tempur dalam Praktek Klinis 2016: 189-224.

2. Pfeifer R, Heussen N, Michalewicz E, dkk. Insiden sindrom gangguan pernapasan dewasa pada pasien trauma: Tinjauan sistematis dan meta-analisis selama tiga dekade. J Trauma Acute Care Surg 2017; 83: 496-506.

3. Rendeki S, Molnár TF. Pulmonary Contusion. J Thorac Dis. 2019;11(Suppl 2):S141-51.

4. Zhou D, Qiu J, Liang Y, dkk. Analisis epidemiologi terhadap 9.596 pasien dengan cedera paru-paru akut di Rumah Sakit Militer China. Exp Ada Med 2017; 13: $983-$ 8.
5. Irianto, K. 2012. Anatomi dan Fisiologi. Bandung : Alfabeta

6. Wang S, Ruan Z, Zhang J. A modified rat model of isolated bilateral pulmonary contusion Exp Ther Med 2012;4:425-9.

7. Onat S, Ulku R, Avci A, dkk. Torakotomi darurat untuk trauma tembus dada: analisis 158 pasien dari satu pusat. Cedera 2011; 42: 900-4.

8. Pfeifer R, Heussen N, Michalewicz E, et al. Incidence of adult respiratory distress syndrome in trauma patients: A systematic review and meta-analysis over a period of three decades. J Trauma Acute Care Surg 2017;83:496-506.

9. Rendeki S, Tamas F. Molnar. Pulmonary contusion. Journal of Thoracic Disease. 2019(11):141-151

10. Hashimoto S, Sanui M, Egi M, et al. The clinical practice guideline for the management of ARDS in Japan. J Intensive Care 2017;5:50.

11. Lichtenberger JP, Kim AM, Fisher D, et al. Imaging of Combat-Related Thoracic Trauma - Blunt Trauma and Blast Lung Injury. Mil Med 2018;183:89-96.

12. Staub LJ, Biscaro RR, Kaszubowski E, et al. Chest ultrasonography for the emergency diagnosis of traumatic pneumothorax and haemothorax: A systematic review and meta-analysis. Injury 2018;49:457-66.

13. Duggal A, Perez P, Golan E, et al. Safety and efficacy of noninvasive ventilation in patients with blunt chest trauma: a systematic review. Crit Care 2013;17:142.

14. Reade MC. Thoracic Trauma and Management of Ventilation in the Critically Injured Patient. Trauma and Combat Critical Care in Clinical Practice 2016:189-224.

15. Miller AC, Elamin EM, Suffredini AF. Inhaled anticoagulation regimens for the treatment of smoke inhalation-associated acute lung injury: a systematic review. Crit Care Med 2014;42:413-9.

16. Eastern Association for the Surgery of Trauma. Pulmonary Contusion and Flail 
Chest, Management of. November 2012.

Available

from:

https://www.east.org/education/practice-

management-guidelines/pulmonary-

contusion-and-flail-chest,-management-of.

[3 Februari 2020] 